\title{
Sobre la acción y el efecto del verbo*
}

JOSEFA MARTÍN GARCÍA

Universidad Autónoma de Madrid

\section{INTRODUCCIÓN}

Es práctica habitual en algunos diccionarios de español recurrir a la paráfrasis 'acción y efecto de V' para definir las nominalizaciones de acción, es decir, los nombres derivados formados a partir de un verbo con la intervención de distintos sufijos nominales (decoración, planteamiento, soldadura, aterrizaje). Como definición morfosemántica, dicha paráfrasis tiene la ventaja de evitar la repetición de la información consignada en la entrada del verbo. Su fin es exclusivamente descodificador, pues solo nos informa del significado composicional de la palabra derivada definida. Si la nominalización hereda todos los sentidos del verbo base, este tipo de definición es adecuada; no lo es, en cambio, cuando la nominalización no hereda alguno de los significados de la base verbal, lo cual puede originar malas interpretaciones. Por ejemplo, una nominalización como aclaración solo se refiere al sentido de aclarar 'hacer algo más comprensible', pero no al significado de 'lavar la ropa con agua para quitarle el jabón', a partir del cual se construye la nominalización aclarado. Una definición de aclaración como 'acción y efecto de aclarar' no refleja la restricción mencionada.

Por otro lado, algunos diccionarios de español junto con la paráfrasis 'acción y efecto de V' presentan otras variantes: 'acción de V', 'acción y resultado de V', 'estado de V', 'hecho de V', 'acto de V', entre otras. Asimismo, es fácil advertir que, en algunos casos, existen discrepancias en las definiciones de una misma nominalización, como muestran los ejemplos siguientes:

a.conocimiento $1 . \mathrm{m}$. Acción y efecto de conocer. $D R A E$

b.conocimiento 1. Acción de conocer. 2 Efecto de conocer, o presencia en la mente de ideas acerca de una cosa. $D U E$

c. conocimiento 1 Hecho de conocer(se). Tb su efecto. DEA

d.conocimiento 1 Acción de conocer. DLE

\footnotetext{
* Una parte de este trabajo fue presentada en el Seminario de Lexicografía en el CILUS, Universidad de Salamanca. Expreso mi agradecimiento a los asistentes al seminario por sus valiosos comentarios. El estudio que aquí se presenta se ha desarrollado dentro del proyecto de investigación «Léxico, sintaxis y variación morfológica: las nominalizaciones deverbales» (FFI2008-00603/FILO), financiado por el Ministerio de Ciencia e Innovación. 
El presente trabajo tiene como objetivo mostrar que la información morfológica de las nominalizaciones de acción puede contribuir a precisar la definición de estas palabras derivadas. Para alcanzar este fin, hemos dividido el artículo en cuatro apartados. En el primero, presentaremos las características morfológicas de las nominalizaciones relevantes para su tratamiento lexicográfico. En el segundo, resumiremos la forma en que las nominalizaciones han sido codificadas en los diccionarios de español a partir de ejemplos tomados de seis diccionarios. En el tercero, nos centraremos en los problemas que plantean las nominalizaciones desde el punto de vista lexicográfico. Terminaremos el trabajo con unas consideraciones finales sobre la codificación de tales palabras derivadas.

\section{CARACTERÍSTICAS MORFOLÓGICAS DE LAS NOMINALIZACIONES DE ACCIÓN Y RESUL- TADO}

Como sabemos, las nominalizaciones de acción ${ }^{1}$ están formadas mediante la adjunción de un sufijo nominalizador al tema verbal (pensa-miento, decora-ción, aterriza-je) $\mathrm{y}$, de forma menos productiva, sin la mediación de un sufijo, esto es, se construyen directamente sobre la raíz verbal (perdón) o con la adición de las terminaciones $-o,-a$, -e (entierr-o, ayud-a, cierr-e), en las denominadas formas postverbales. En varios casos, una misma base verbal da lugar a dos nominalizaciones con la intervención de sufijos distintos (agrupación / agrupamiento) o bien mediante variantes del tema verbal (abertura / apertura).

Desde el punto de vista semántico, las nominalizaciones de acción pueden interpretarse en un sentido eventivo (2a) o no eventivo (2b):

a.La construcción del puente duró varios meses.

b.Las construcciones de este pueblo no son de buena calidad.

Varias nominalizaciones como las de (2) presentan esta doble interpretación. No obstante, en algunos casos, la morfología distingue estos dos significados mediante procesos distintos, de modo que haya una forma para la interpretación eventiva del nominal y otra para la no eventiva (formulación / fórmula). Otra posibilidad es que cada formación aluda a un significado concreto del verbo, como vemos en (3):

a.La ruptura de la negociación (romper las relaciones)

b.La rotura del cristal (romper algo material)

\footnotetext{
${ }^{1}$ Sobre las nominalizaciones se ha publicado un número considerable de trabajos desde distintas perspectivas y enfoques. En este apartado solo comentaremos las características más relevantes para la práctica lexicográfica, tomadas de estudios como Grimshaw (1990), Picallo (1999), Alexiadou (2001), entre muchos otros. Para el español, seguimos los trabajos de Monge (1970), Pena (1980), Fernández Ramírez (1986), Rainer (1993), Santiago Lacuesta y Bustos Gisbert (1999), NGRAE.
} 
c.El rompimiento de las olas (romper las olas en las rocas)

Las nominalizaciones eventivas denotan un proceso que ocurre o tiene lugar, de ahí que en la oración se combinen con predicados como tener lugar, durar, ocurrir, etc. (4a) o bien con adjuntos temporales sin la preposición de (4b).

(4)

a.La traducción de la novela tuvo lugar en 1989.

b.La explicación de la crisis ayer por parte de la vicepresidenta duró media hora. ${ }^{2}$

Al denotar la acción del verbo, la nominalización eventiva hereda los argumentos de la base verbal, por lo cual la nominalización va a ser capaz de expresar las mismas funciones semánticas que el verbo del que procede (5a), presenta adjuntos temporales sin preposición (5b) y suele construirse con el artículo definido (5c):

\section{(5)}

a. La vicepresidenta explicó la crisis durante media hora $>$ La explicación de la crisis por parte de la vicepresidenta duró media hora.

b.La explicación de la crisis ayer por parte de la vicepresidenta duró media hora.

c. $\{$ La / *Aquella / *Esta / *Una $\}$ explicación de la crisis por parte de la vicepresidenta duró media hora.

Asimismo, dentro de la herencia de las propiedades sintáctico-semánticas del verbo se incluyen también los sintagmas preposicionales regidos (6a-b), así como el modo verbal en el que aparecen las oraciones seleccionadas por el verbo (6c-d):

(6)

a.Los niños salen de su casa a las 17:00 horas. $>$ [La salida de los niños de su casa a las 17:00 horas] tuvo lugar ayer.

b.El químico combinó el azufre con el hierro durante varios minutos. > [La combinación del azufre con el hierro por parte del químico] duró varios minutos.

c. Juan concluyó que todo era mentira. > Llegó a [la conclusión de que todo era mentira].

d.Espero que todo vaya bien. > Tengo [la esperanza de que todo vaya bien].

Frente a las nominalizaciones eventivas, las no eventivas no indican un proceso, por lo que la herencia de las propiedades sintáctico-semánticas está más restringida. Dentro de este grupo de nominalizaciones es posible distinguir varios tipos. En primer lugar, hay que destacar las nominalizaciones de resultado, definidas en distintos trabajos a partir de la negación de las propiedades que caracterizan una nominalización eventiva (Grimshaw 1990). Así, a diferencia de las nominalizaciones eventivas, las de resultado

\footnotetext{
${ }^{2}$ La nominalización no eventiva requiere la preposición de: La explicación de la crisis de ayer no convenció a nadie.
} 
no tienen estructura argumental (7a), admiten distintos determinantes (7b), pueden pluralizarse $(7 \mathrm{c})$ y llevan adjuntos temporales con preposición $(7 \mathrm{~d})$ :

(7)

a. La construcción (*del puente) se derrumbó. / La construcción del puente duró varios meses.

b. \{La / Aquella / Esa / Una $\}$ construcción se derrumbó. / \{La / *Aquella / Esa / *Una\} construcción del puente duró varios meses.

c. Las construcciones se derrumbaron. / * Las construcciones del puente duraron varios meses.

d.La construcción del año pasado se derrumbó / La construcción del puente el año pasado duró varios meses.

El resultado que denotan estas nominalizaciones puede entenderse como una entidad física, es decir, como un objeto resultado obtenido tras la culminación de la acción, o bien como un estado resultado al que se llega al tener lugar la acción sobre el argumento interno. En el primer caso, las nominalizaciones de objeto resultado proceden de verbos de objeto efectuado (construir), cuyo argumento interno denota, efectivamente, una entidad que se constituye como el resultado de la acción (construcción), y de verbos resultativos de creación (traducir), en los que el argumento interno se ve afectado por la acción y da lugar a un objeto resultado (traducción). Solo estas últimas nominalizaciones heredan el argumento interno del verbo, dado que las primeras absorben dicho argumento: ${ }^{3}$

a.Los albañiles han construido un edificio $>$ una construcción $(*$ del edificio) muy alta.

b.El escritor ha traducido la novela $>$ Leímos la traducción de la novela.

Las nominalizaciones de estado resultado denotan el estado final en que se encuentra el argumento interno del verbo una vez culminada la acción; en consecuencia, van a heredar el argumento del verbo y, como estados, son susceptibles de ser modificados por complementos temporales durativos: El barco encalló en el arrecife > la encalladura del barco en el arrecife durante varios dias.

En segundo lugar, junto con las nominalizaciones de resultado, existen otras nominalizaciones no eventivas que no indican un resultado de la acción, sino que expresan

\footnotetext{
${ }^{3}$ Según Bisetto y Melloni (2007), las nominalizaciones de objeto resultado procedentes de verbos resultativos de creación absorben el estado resultado del verbo, por lo que pueden heredar el argumento interno. No todos los autores defienden que las nominalizaciones de objeto resultado lleven argumentos. Para Grimshaw (1990), la ausencia de argumentos era, precisamente, una de las características que diferenciaba las nominalizaciones eventivas de las de resultado. En la $N G R A E$ se señala que las nominalizaciones de resultado que expresan una representación llevan un argumento paciente, dado que puede haber varias realizaciones del objeto representado en el argumento interno del verbo. Así, frente a una única construcción de un edificio, es posible tener varias traducciones de un mismo libro.
} 
diversos contenidos significativos, como objetos (9a) y estados (9b) no resultantes de la acción significada en la base verbal, lugares $(9 \mathrm{c})$ o instrumentos $(9 \mathrm{~d}):^{4}$

(9)

a. Rompió la envoltura del paquete.

b.El mantenimiento de los tipos de interés da estabilidad a la economía.

c. El barco atravesó la desembocadura del río.

d.No funciona la iluminación de la calle.

Este último grupo de nominalizaciones presenta un significado menos sistemático que el de las nominalizaciones eventivas y de resultado, pues en muchos casos no es un significado composicional. Así, la interpretación de la nominalización envoltura como 'objeto con el que se envuelve algo' no se deduce de manera natural de los elementos que conforman la palabra derivada. Tampoco es sistemática la creación de tales nominales, frente a la alta productividad de las nominalizaciones eventivas y de resultado. Por ejemplo, no tenemos nominalizaciones de estado a partir de verbos de estado como ser, tener o pertenecer. Asimismo, las nominalizaciones deverbales de lugar son muy poco productivas y están formadas a partir de sufijos nominales que no expresan de forma regular dicha noción: el sufijo -dura, presente en desembocadura, designa nominalizaciones de resultado y, de forma muy marginal, el lugar donde se desarrolla la acción.

3. LAS NOMINALIZACIONES DE ACCIÓN Y RESULTADO EN LOS DICCIONARIOS DE ESPAÑL

La paráfrasis 'acción y efecto de $\mathrm{V}$ ' está construida mediante la coordinación de dos nociones: la acción y el efecto del verbo. Como fórmula definitoria, aparece ya utilizada en la definición de las nominalizaciones deverbales en el Diccionario de autoridades (10a), si bien su uso es esporádico. Por otro lado, en este diccionario académico los definidores acción y efecto se combinan con distintos sinónimos (10b-c), como ya señaló Ribera (1918):

\section{(10) Diccionario de autoridades}

a.cortamiento: El acto y efecto de cortar alguna cosa.

b.apagamiento: El acto de apagar y extinguir alguna cosa; y también significa el mismo efecto de quedar la luz o llama apagada.

\footnotetext{
${ }^{4}$ Como muestran los ejemplos de (9), no es posible identificar toda nominalización no eventiva como una nominalización de resultado. Varios autores han puesto de relieve la necesidad de reconocer distintos tipos de nominalizaciones con el fin de superar la clasificación bipartita entre nominalización de evento y de resultado. Por ejemplo, Van Hout (1991) o Azpiazu (2004) señalan distintos tipos de nominalización según las propiedades verbales y nominales que presente la forma. Se concibe así la nominalización como un proceso gradual en el que el nominal comienza a tener más propiedades nominales y menos propiedades verbales.
} 
c. apresamiento: El acto de apresar y tomar por fuerza alguna cosa. Y también denota el efecto de la cosa apresada, como el apresamiento de una galera, de una embarcación, etc.

El intento de precisar las nociones de acción y efecto en el Diccionario de autoridades contrasta con la utilización, a veces abusiva, de la paráfrasis 'acción y efecto de $\mathrm{V}$ ' en las distintas ediciones del diccionario académico. Véase a este respecto las definiciones de la edición de (1780), las cuales se conservan hasta la última edición del diccionario académico:

(11) Diccionario de la lengua castellana (1780)

a.apagamiento: La acción y efecto de apagar.

b.apresamiento: La acción y efecto de apresar.

La paráfrasis 'acción y efecto de V' se utiliza para definir las nominalizaciones que proceden tanto de un verbo (12a) como de una nominalización propiamente latina (12b):

a.calcificación: (De calcificar) Acción y efecto de calcificar o calcificarse. DRAE

b.abolición: (Del lat. abolitio, -ōnis) Acción y efecto de abolir. DRAE

En los casos como el que representa (12b), se produce un desajuste entre la información contenida en el paréntesis etimológico y la definición morfosemántica, dado que, según la etimología, la nominalización es una formación propiamente latina; en cambio, en la definición se trata la nominalización como una forma deverbal.

El diccionario académico no es el único que utiliza la paráfrasis 'acción y efecto de $\mathrm{V}$ ' en las definiciones de las nominalizaciones de acción y resultado, sino que dicha paráfrasis se encuentra también, por ejemplo, en las tres ediciones del $D U E:^{5}$

a.agudización: Acción y efecto de agudizar[se]. DUE

b.enamoramiento: Acción y efecto de enamorar[se]. DUE2

c.limitación: Acción y efecto de limitar[se]. DUE3

En algunos diccionarios, se adopta la paráfrasis en cuestión solo parcialmente, dado que se añaden modificaciones en una de las dos partes que componen la definición. Por ejemplo, en el DSLE se sustituye la palabra efecto por resultado (14a) o en el $D E A$ se mantiene la primera parte de la fórmula 'acción de $\mathrm{V}$ ' y el efecto se añade como posibilidad rompiendo, así, la coordinación (14b):

\footnotetext{
${ }^{5}$ No obstante, el $D U E$ utiliza la paráfrasis en cuestión con menor frecuencia que el $D R A E$, como bien se muestra en el trabajo de Díaz Hormigo (1998).
} 
(14)

a.traducción: Acción y resultado de traducir. DSLE

b.constatación: Acción de constatar. Tb su efecto. DEA

Otra posibilidad que presentan algunos diccionarios de español es considerar las dos partes coordinadas de la paráfrasis como acepciones distintas:

a.conocimiento: Acción de conocer. 2. Efecto de conocer, o presencia en la mente de i $D E A$ s a cerca de una cosa. $D U E$

b.acuñación: 1 Acción de acuñar. 2 Efecto de acuñar. $D L E$

Como hemos señalado en el apartado anterior, algunas nominalizaciones son ambiguas al presentar una lectura de acción y otra de resultado. No obstante, hay nominalizaciones con una interpretación exclusivamente eventiva, por lo cual solo pueden ser definidas mediante una parte de la paráfrasis, aquella que hace referencia, precisamente, a la acción. Es frecuente, por tanto, en los diccionarios de español encontrar muchas definiciones construidas con la estructura 'acción de V':

a.aterrizaje: Acción de aterrizar. DSLE

b.actualización: Acción de actualizar. $D E A$

c. calentamiento: Acción de calentar. DRAE

d.centralización: Acción de centralizar. DUE

e. funcionamiento: Acción de funcionar. DLE

En algunos casos, se acota la extensión del verbo base al incluir en la definición los argumentos:

a.compra: Acción de comprar. Acción de comprar los alimentos necesarios. DEA

b.construcción: 1 Acción de construir. 2 Actividad de construir edificios o cosas similares. $D E A$

Las nominalizaciones de objeto resultado, por su parte, suelen estar definidas mediante las paráfrasis 'acción y efecto de V' o 'acción de V', seguida de otra acepción en la que se explica el objeto resultado:

a.expropiación: Acción y efecto de expropiar. 2. Cosa expropiada. DRAE

b.adquisición: Acción de adquirir. 2. Cosa adquirida. DUE

c.traducción: 1 Acción de traducir. 2 Obra o discursos traducidos. DLE

d.producción: 1 Acción de producir. 2 Cosa o conjunto de cosas producidas. DEA 
No todas las nominalizaciones de acción y de resultado, aun exhibiendo un significado composicional, aparecen definidas mediante una definición morfosemántica, como vemos en los siguientes ejemplos:

a. acogida: Recibimiento público. DSLE

b.desciframiento: Interpretación de un conjunto de signos cifrados. $D L E$

c.descubrimiento: Hallazgo, encuentro, manifestación de lo que estaba oculto o secreto o era desconocido. 2. Encuentro, invención o hallazgo de una tierra o un mar no descubierto o ignorado. DRAE

Como puede apreciarse en los ejemplos de (19), las definiciones están construidas utilizando como definidores nominalizaciones de acción y resultado. La elección de las nominalizaciones incluidas en las definiciones suele estar motivada por los verbos definidores utilizados en la definición del verbo del que procede la nominalización, como podemos comprobar en las definiciones de los verbos de (20), de los que proceden las nominalizaciones de (19) acogida y descubrimiento:

a. acoger: Recibir una persona a una persona o una cosa de una manera determinada. DSLE

b.descubrir: 1 Manifestar, hacer patente. 3. Hallar lo que estaba ignorado o escondido, principalmente tierras o mares desconocidos. DRAE

En algunos casos, la definición de la nominalización es paralela a la definición del verbo base:

a.manufacturación: Fabricación o elaboración de un producto manualmente o con medios mecánicos a partir de materias primas. DLE

b.manufacturar: Fabricar o elaborar un producto manualmente o con medios mecánicos a partir de materias primas. $D L E$

En algunos diccionarios como el DUEA, se utiliza de forma sistemática las definiciones no morfosemánticas para las nominalizaciones de acción y resultado, de modo que se descarta en todos los casos la paráfrasis 'acción y efecto de V'. Dado que las nominalizaciones se definen mediante otras nominalizaciones, puede producirse cierta circularidad, como ocurre en las siguientes definiciones del DUEA:

a.construcción: Fabricación o realización de algo, esp. de una obra de albañilería, juntando los elementos necesarios para ello.

\footnotetext{
${ }^{6}$ En esta nominalización, el $D R A E$ no adopta una definición morfosemántica, a pesar de que en el paréntesis etimológico se especifica el origen deverbal de la palabra derivada definida.
} 
b.fabricación: 1 Producción en serie y generalmente por medios mecánicos. 2 Construcción, preparación o creación de algo.

c.producción: 2 Fabricación o elaboración de un objeto.

d.elaboración: 1 Preparación, transformación o producción de algo por medio del trabajo adecuado. 2 Invención, diseño o creación de algo complejo, esp. de un proyecto.

e.creación: 2 Producción de algo a partir de la nada o realización de algo a partir de las propias capacidades.

Por último, como hemos visto en el apartado anterior, varias nominalizaciones deverbales no tienen una interpretación eventiva ni de resultado, por lo cual no pueden estar definidas mediante la paráfrasis 'acción y efecto de V'. En estos casos, las definiciones se construyen sobre hiperónimos como lugar, dispositivo, etc.:

a.desembocadura: Lugar en el que una corriente de agua desemboca en otra, en el mar o en un lago. DLE

b.amortiguación: En una máquina, dispositivo que sirve para compensar y disminuir el efecto de choques, sacudidas o movimientos bruscos. DRAE

\section{PROBLEMAS EN LA CODIFICACIÓN}

Hemos visto en el apartado anterior el modo en que distintos diccionarios de español definen las nominalizaciones de acción y resultado. Es el momento de tratar los problemas que plantea, por un lado, la inclusión de las nominalizaciones en el diccionario y, por otro, la utilización de la paráfrasis 'acción y efecto de $\mathrm{V}$ ' en las definiciones.

\subsection{Las acepciones del verbo base}

La paráfrasis 'acción y efecto de V' supone admitir que la nominalización hereda todos los significados del verbo base. Así, la definición de anulación recogida en (24b) alude a las cuatro acepciones del verbo anular (24a). En (25), se recogen ejemplos de dicha nominalización en sus distintos significados.

a. anular: 1. Dar por nulo o dejar sin fuerza una disposición, un contrato, etc. 2. Suspender algo previamente anunciado o proyectado. 3. Incapacitar, desautorizar a alguien. 4. Retraerse, humillarse o postergarse. $D R A E$

b.anulación: Acción y efecto de anular o anularse. $D R A E$

(25)

a.El director anuló el contrato $>$ la anulación del contrato

b.El famoso anuló la rueda de prensa $>$ la anulación de la rueda de prensa

c.El presidente del equipo anuló al entrenador $>$ la anulación del entrenador 
d.El niño se anula ante sus compañeros de clase > la anulación del niño

Sin embargo, no todas las nominalizaciones heredan cada uno de los significados del verbo base, sino que se construyen a partir de ciertas acepciones. Así, tomando el ejemplo de Lázaro Carreter (1971), la nominalización casamiento solo procede del significado de casar 'contraer matrimonio', no del sentido 'unir dos cosas'. En consecuencia, la formación casamiento no puede estar definida como 'acción y efecto de casar', sino que es necesario especificar la acepción del verbo. En los diccionarios de español, no se especifica de formar regular la acepción de la base de donde procede la nominalización, como mostramos en (26):

\section{(26)}

a.casamiento: Acción y efecto de casar ( $\|$ contraer matrimonio). DRAE

b.casamiento: Acción de casar(se). DUE3

c. casamiento: Acción y efecto de casar o casarse. $D L E$

d.casamiento: Acción de casar(se). DEA

El hecho de que los procesos de formación de palabras se construyan sobre significados concretos de la base tiene importantes consecuencias a la hora de establecer las familias de palabras. En el caso de las nominalizaciones, puede ocurrir que distintas acepciones del verbo den lugar a nominalizaciones diferentes. Por ejemplo, el verbo aclarar tiene dos nominalizaciones procedentes de acepciones distintas. A partir del significado 'hacer algo más comprensible' se crea la nominalización aclaración; las acepciones 'lavar la ropa con agua para quitarle el jabón' o 'hacer más clara la voz' son la base para aclarado. Algunos diccionarios de español como el $D E A$ especifican las acepciones del verbo de las que procede una y otra nominalización (27a, b); en otros, en cambio, solo se acota la extensión de aclarado al especificar el complemento de aclarar (27d) o explicando el significado del verbo (27f):

a.aclaración: Acción de aclarar [4, 5 y 6]. Tb su efecto. DEA

b.aclarado: Acción de aclarar [1, 2 y 3 esp. 2]. DEA

c. aclaración: Acción de aclarar. DUE3

d.aclarado: Acción de aclarar la ropa. DUE3

e.aclaración: Acción y efecto de aclarar o aclararse. $D R A E$

f. aclarado: Acción y efecto de aclarar (\| volver a lavar la ropa con agua sola). DRAE

Dado que las nominalizaciones, en cuanto palabras derivadas, proceden de acepciones concretas de la base, cabe esperar que presenten más de un significado en el caso de que se hayan derivado a partir de más de una acepción del verbo base. En algunas nominalizaciones de este tipo, se diferencian distintas acepciones en el artículo lexicográfico correspondiente, como vemos a propósito de creación en el DRAE: 
creación: 1. Acción y efecto de crear (\| establecer). 2. Acción y efecto de crear (\| instituir). 3. Acción de crear (\| hacer a alguien lo que antes no era). 4. Acto de criar o sacar Dios algo de la nada.

En los casos en que no se utiliza la paráfrasis 'acción y efecto de V', la definición de la nominalización puede construirse a partir de la nominalización de los verbos definidores del verbo base, de modo que la definición obtenida es paralela a la del verbo base, como ocurre en las siguientes definiciones tomadas del DLE:

\section{(29) producción}

a.Fabricación o elaboración de un producto mediante el trabajo.

b.Fabricación o elaboración de una sustancia u otra cosa que resulta útil para uno mismo.

c.Financiación de los gastos que supone realizar una película, un programa de radio o televisión, un espectáculo teatral, etc., o suministro del equipo y el personal necesarios para ello.

d.Creación de una obra de arte.

\section{(30) producir}

a. Fabricar o elaborar un producto mediante el trabajo.

b. Fabricar o elaborar una sustancia u otra cosa que resulta útil para uno mismo.

c. Financiar los gastos que supone realizar una película, un programa de radio o televisión, un espectáculo teatral, etc., o proporcionar el equipo y el personal necesarios para ello.

d. Hacer [una persona] una obra de arte.

\subsection{Nominalizaciones de resultado}

Según hemos comentado ya en secciones anteriores, la denominación 'acción de V' hace referencia a la interpretación de las nominalizaciones eventivas, mientras que el efecto del verbo alude a la lectura como nominalización de resultado. Uno de los problemas que origina esta segunda parte de la paráfrasis definicional que analizamos es que bajo la noción de efecto solo puede incluirse una parte de las nominalizaciones no eventivas, aquellas que indican, precisamente, un resultado de la acción, bien como un objeto resultado, bien como un estado resultado. El resto de nominalizaciones que no indican propiamente una acción ni un resultado no pueden ser definidas mediante esta paráfrasis. ${ }^{7}$ Como ya señaló acertadamente Ribera (1918), el significado de efecto indica siempre un hecho y, en el caso de un verbo transitivo, el efecto es un hecho del paciente. No obstante, este hecho resultado también es posible con verbos intransitivos que no culminan en un resultado, pero que denotan resultados en la sucesión de eventos significados. En consecuencia, las nominalizaciones correspondientes también son nominalizaciones de resultado (lameduras, chorreaduras) (Martín García, 2011).

\footnotetext{
${ }^{7}$ En la Presentación del $D U E$, señala María Moliner que, bajo el término efecto, no pueden incluirse nociones como estado, cosa hecha, causa y otras muchas más.
} 
Algunas nominalizaciones como las de (31) son definidas exclusivamente como nominalizaciones eventivas, a pesar de su interpretación de resultado:

a.adopción: Acción de adoptar. DUE3

b.argumentación: Acción de argumentar. DRAE

c. verificación: Acción de verificarse. $D E A$

En otros casos, se definen con la paráfrasis 'efecto de V' nominalizaciones que no son de resultado: bien porque proceden de verbos estativos (32a), bien porque la nominalización solo tiene una interpretación eventiva $(32 b)$ :

a.residencia: Acción y resultado de residir o vivir en un lugar. DSLE

b.seguimiento: Acción y efecto de seguir o seguirse. DRAE

\subsection{Nominalizaciones procedentes de verbos de estado}

Los verbos de estado indican situaciones que duran en el tiempo sin que progresen, a diferencia de los verbos dinámicos. Por dicha razón, los verbos de estado no dan lugar a nominalizaciones que expresen eventos o procesos, sino solo a nominalizaciones que denotan hechos o estados. Del mismo modo, dado que dichos verbos representan situaciones que no culminan en un final, no pueden originar nominalizaciones de resultado. No obstante, en algunos diccionarios las nominalizaciones procedentes de verbos de estado suelen estar definidas mediante la paráfrasis 'acción y efecto de $\mathrm{V}$,, como muestran las definiciones siguientes:

a.conocimiento: Acción de conocer. $D L E$

b.permanencia: Acción de permanecer. DEA

c.residencia: Acción y resultado de residir o vivir en un lugar. DSLE

d.sentimiento: Acción y efecto de sentir o sentirse. DRAE

En otras ocasiones, las definiciones de las nominalizaciones de estado se construyen a partir de los sustantivos definidores estado, hecho o circunstancia, sin recurrir a la habitual paráfrasis 'acción y efecto de V'. Tales definidores son los más apropiados para las nominalizaciones de verbos de estado, dado que son compatibles con las propiedades semánticas de un estado como son la duración, la atelicidad y la no dinamicidad, según se muestra en Jaque Hidalgo (en prensa):

a.conocimiento: Hecho de conocer(se). DEA

\footnotetext{
${ }^{8}$ García García-Serrano (2003) califica este hecho de 'incoherencia gramatical' y aporta varios ejemplos de nominalizaciones de estado definidas como acciones.
} 
b.existencia: Circunstancia de existir. DUE3

c.falta: Circunstancia de no haber una cosa o existir poca cantidad. DSLE

d.sentimiento: Estado de ánimo o disposición emocional hacia una cosa, un hecho o una persona. $D L E$

e.vivencia: 2 Hecho de vivir o estar vivo. DRAE

Algunos verbos con significados estativos (35a-b) y significados de acción (35c) dan lugar a una única nominalización para los distintos sentidos:

a. Sigue manteniendo la misma idea desde hace años. $>$ El mantenimiento de su idea le costará muchos disgustos.

b.Mantiene muy bien el viejo coche. $>$ El mantenimiento del viejo coche es muy costoso.

c. Mantiene a toda la familia. > Necesita dinero para el mantenimiento de la familia.

En estos casos, la definición de la nominalización debe aludir al significado del verbo base, como ocurre en el siguiente ejemplo.

(36)

mantenimiento: 1 Conservación de una cosa en buen estado o en una situación determinada para evitar su degradación. 2 Acción de mantener a una persona (proporcionarle el alimento o lo necesario para vivir). 3 Hecho de mantener o mantenerse una cosa en determinado estado o situación. $D L E$

\subsection{Nominalizaciones con prefijo}

Algunas nominalizaciones presentan un prefijo además del sufijo nominalizador. Tales formaciones pueden ajustarse a dos estructuras morfológicas, a cada una de las cuales le corresponde una interpretación: en una, la nominalización procede de un verbo prefijado (37a), por tanto, despliega el significado 'acción de V'; en otra, la nominalización se construye sobre un verbo sin prefijo y, posteriormente, a partir del sentido no eventivo, se forma un nombre prefijado (37b):

a. [ [des [abasteci $\left.]_{\mathrm{V}}\right]_{\mathrm{V}}$ miento $]_{\mathrm{N}} \quad$ 'acción de desabastecer'

b. $\left.\left[\text { des }[\text { [abasteci }]_{\mathrm{V}} \text { miento }\right]_{\mathrm{N}}\right]_{\mathrm{N}} \quad$ 'falta de abastecimiento'

Los diccionarios suelen presentar discrepancias a la hora de definir estas formaciones, como vemos en los siguientes ejemplos:

a.desabastecimiento: Acción de desabastecer(se). Tb su efecto. DEA

b.desabastecimiento: Falta de abastecimiento. DUE 
(39)

a.autoabastecimiento: Acción de autoabastecerse. $D E A$

b.autoabastecimiento: Sistema de abastecimiento en el que los propios recursos son suficientes. $D L E$

Las definiciones de (38a) y (39a) se atienen a un proceso morfológico como el reflejado en (37a), según el cual la nominalización procede de una base verbal prefijada. Las definiciones recogidas en (38b) y (39b), por el contrario, aluden a un proceso morfológico como el descrito en (37b), es decir, son nominalizaciones prefijadas.

Algunas nominalizaciones presentan la doble estructura de (37); otras, en cambio, solo una de ellas, bien como nominalizaciones del verbo prefijado (encuadernar $>$ reencuadernar $>$ reencuadernación, lo mismo en desencadenamiento, desaparición), bien como nominalizaciones prefijadas (conocer $>$ conocimiento $>$ desconocimiento, también en descoordinación, autofinanciación).

\subsection{Nominalizaciones procedentes de un mismo verbo}

Como hemos visto ya, la nominalización, como proceso morfológico, procede de acepciones concretas del verbo. Una consecuencia de ello es que una misma nominalización tenga como origen distintos significados del verbo, de modo que la nominalización será ambigua. Así, la nominalización elaboración tiene al menos tres significados heredados del verbo: 'preparación de productos', 'formulación de una teoría' y 'producción de una sustancia por parte de un cuerpo'.

Otra consecuencia es que un mismo verbo dé lugar a más de una nominalización, según las acepciones que el verbo contenga. Es lo que ocurre, por ejemplo, con el verbo romper, base de nominalizaciones como ruptura, rotura, rompimiento o rompedura, ya en desuso. El verbo romper tiene varias acepciones, de las cuales solo tres se constituyen como base para las nominalizaciones, como vemos en (40):

(40) romper

1.Separar o hacer pedazos un objeto físico. $\rightarrow$ La rotura del cristal

2.Interrumpir la continuidad de una situación. $\rightarrow$ La ruptura del matrimonio

3.Deshacerse las olas en espuma. $\rightarrow$ El rompimiento de las olas

Dado que, con frecuencia, no se suelen marcar las acepciones del verbo de donde procede el nombre deverbal, las distintas nominalizaciones de una misma base acaban definidas del mismo modo, como vemos en el siguiente ejemplo:

(41) DRAE

a.rotura: Acción y efecto de romper o romperse. 2. Raja o quiebra de un cuerpo sólido.

b.ruptura: Acción y efecto de romper o romperse. 2. Rompimiento de relaciones entre personas.

c.rompimiento: Acción y efecto de romper o romperse. 
d.rompedura: Acción y efecto de romper o romperse.

En otros casos, simplemente se establece una remisión entre las distintas nominalizaciones de un verbo:

(42) DRAE

a.acotación: acotamiento

b.acotamiento: Acción y efecto de acotar.

\section{CONSIDERACIONES FINALES}

Como hemos visto en distintas partes de este trabajo, las nominalizaciones de acción presentan una doble naturaleza en cuanto que denotan acción y resultado, además de otros contenidos semánticos. En su interpretación de acción o evento, heredan la estructura argumental del verbo base y exhiben un significado composicional. Como nominalizaciones no eventivas, la herencia de los argumentos está sometida a más restricciones y el significado puede experimentar extensiones significativas no predecibles: resultado, hecho, objeto, estado, actitud, etc. Tales nociones pueden hacer referencia, a su vez, a distintas relaciones semánticas. Por ejemplo, la nominalización de resultado puede dar lugar a un objeto que aluda tanto al paciente como a la causa: construcción (= 'cosa construida'), entretenimiento (= 'cosa que entretiene'). Tales características separan las nominalizaciones de otros procesos morfológicos con un significado más preciso, como los adjetivos en -ble o los adverbios en -mente.

Con los procesos morfológicos productivos con un significado estable y fácilmente predecible, el lexicógrafo puede plantearse si las palabras derivadas deben estar recogidas en la macroestructura del diccionario. En relación con las nominalizaciones, se ha asumido de forma unánime que tales palabras derivadas deben estar listadas con una entrada propia en los diccionarios. No obstante, en algunos diccionarios como la primera edición del $D U E$, están excluidas de la macroestructura varias nominalizaciones de acción y otras aparecen listadas en la familia etimológica sin definición, solo especificando que son de significado deducible del verbo del que proceden. En las dos ediciones posteriores del $D U E$, las nominalizaciones excluidas en la primera edición son incluidas en la macroestructura y definidas con las paráfrasis 'acción y efecto de $\mathrm{V}$ ' o 'acción de V'.

La opción de excluir de la macroestructura las nominalizaciones de acción es defendida también en el trabajo de Lázaro Carreter (1971). Según este autor, las nominalizaciones deben aparecer como una remisión desde la propia acepción del verbo, es decir, en la microestructura del verbo base, pero no en la macroestructura del diccionario. De este modo, en cuanto palabras de significado predecible, a partir de la estructura de la palabra es posible componer el significado. No obstante, esta solución es válida para las nominalizaciones con una interpretación eventiva, pero no lo es para las nominalizaciones no eventivas, cuya interpretación y uso sintáctico no puede predecirse desde la propia estructura morfológica. Plantean problemas, asimismo, aquellas nominalizaciones cuya forma no sea transparente (ruptura, apertura). En consecuencia, 
asumir esta solución supone codificar las nominalizaciones de acción de dos modos distintos: por un lado, las nominalizaciones con una interpretación de acción estarán recogidas en la microestructura del verbo base; por otro, las nominalizaciones no eventivas aparecerán en la macroestructura con una entrada propia.

Si la opción es incluir las nominalizaciones en la macroestructura, el problema que se plantea es determinar qué información debe contener el artículo lexicográfico. En primer lugar, si se opta por una definición morfosemántica, como la que tratamos en este trabajo, es necesario especificar la acepción del verbo base de la que procede la nominalización. De este modo, al establecer la conexión entre la nominalización y el verbo base, es posible determinar el significado de la nominalización y su proyección sintáctica a partir de la herencia de los argumentos. Por otro lado, dada la ambigüedad de las nominalizaciones de acción, resulta conveniente que cada significado esté recogido en acepciones distintas, como ya defendía Ribera (1918) y como aparece en algunos diccionarios como el $D U E$ o el $D L E$. Asumiendo esta idea, la lectura de acción o proceso puede quedar reflejada mediante la paráfrasis 'acción de V' marcando la acepción del verbo, de modo que se evite la repetición de la definición de la base verbal. Para la lectura de resultado, puede adoptarse también una paráfrasis semejante a la anterior, por ejemplo, 'resultado de V', pero, en este caso, es necesario que la paráfrasis vaya acompañada de explicaciones que completen la paráfrasis (objeto, situación, estado resultado). En otras nominalizaciones no eventivas, será preciso recurrir a otros definidores como hecho, lugar, circunstancia, etc.

Por último, cabría una tercera posibilidad en el tratamiento de las nominalizaciones al fundir las dos soluciones dadas, dotando, así, al diccionario de un carácter descodificador y codificador, en la línea de lo ya esbozado en el trabajo de Martín García (2000). En este sentido, las nominalizaciones aparecerán en la macroestructura para satisfacer las consultas en las que se requiera conocer el significado de la palabra, bien porque no se reconoce la estructura morfológica de la nominalización (ruptura), bien porque no es posible componer el significado a pesar de que la forma sea transparente (habitación). Asimismo, las nominalizaciones estarán recogidas en la acepción del verbo base con el fin de que se pueda construir el significado sin necesidad de acudir al artículo lexicográfico de la nominalización.

\section{REFERENCIAS BIBLIOGRÁFICAS}

AleXIAdoU, Artemis (2001): Functional Structure in Nominals, Amsterdam, John Benjamins.

AZPIAZU, Susana (2004): Las estrategias de nominalización, Frankfurt, Peter Lang.

Battaner, M. Paz, dir. (2001): Diccionario de la lengua española, Barcelona, Spes editorial. $[D L E]$ 
Bisetto, Antonietta y Chiara Melloni (2007): «Result Nominals: a Lexical-Semantic Investigation», en G. Booij et al., eds., On-line Proceedings of the Fifth Mediterranean Morphology Meeting, http://mmm.lingue.unibo.it

DíAz Hormigo, M. TaDEA (1998): «El tratamiento de algunas clases de sustantivos deverbales en el Diccionario de uso del español de María Moliner. (Hacia una clasificación sintáctico-semántica de los sustantivos deverbales)», en M. Casas, I. Penadés y M. T. Díaz, eds., Estudios sobre el Diccionario de uso del español de María Moliner, Cádiz, Universidad de Cádiz, pp. 71-107.

FERNÁNDEZ RAMÍREZ, Salvador (1986): La derivación nominal, Madrid, Anejo XL del Boletín de la Real Academia de la Lengua.

García GarcíA-Serrano, M. Ángeles. (2003): «Los nombres de acción en algunos diccionarios del español», Revista de Lexicografía, X, pp. 81-101.

Grimshaw, Jane (1990): Argument Structure, Cambridge, MIT Press.

GutiÉRrez CuAdrado, Juan, dir. (1996): Diccionario Salamanca de la lengua española, Madrid, Santillana-Universidad de Salamanca. [DSLE]

JAQUE HidALGO, Matías (en prensa): «Las nominalizaciones deverbales estativas en el diccionario monolingüe español», Actas del IV Congreso internacional de lexicografía hispánica, Tarragona, Universidad Rovira Virgili.

LÁZARO CARRETER, Fernando (1971): «Transformaciones nominales y diccionario», Revista Española de Lingüística, 1/2, pp. 371-379.

Maldonado, Concepción, dir. (1996): Diccionario de uso del español actual, Madrid, Editorial SM. [DUEA]

MARTíN GARCíA, Josefa (2000): «La morfología derivativa en la lexicografía española», en F. J. Ruiz de Mendoza, coord., Panorama actual de la lingüística aplicada, Logroño, Universidad de La Rioja, II, pp. 1081-1088.

(2011): «Deverbal nouns with the suffix -dura», en J. L. Cifuentes y S. Rodríguez, eds., Spanish Word Formation and Lexical Creation, Amsterdam, John Benjamins, pp. 165-183.

Moliner, María (1968): Diccionario de uso del español, Madrid, Gredos. [DUE]. (1998) $2^{\circ}$ edición [DUE2]. (2007) $3^{\mathrm{a}}$ edición [DUE3].

Monge, Felix (1970): «Los nombres de acción en español», en A. Rosetti, ed., Actele celui de-al XII-Lea Congres international de Linguistica si Filologie Romanica, Bucarest, Editura Acadiemiei, pp. 961-972. 
PENA, Jesús (1980): La derivación en español. Verbos derivados y sustantivos deverbales, Santiago de Compostela, Universidad de Santiago, anejo 16 de Verba.

PiCALlo, M. Carme (1999): «La estructura del sintagma nominal: las nominalizaciones y otros sustantivos con complementos argumentales», en I. Bosque y V. Demonte, dirs., Gramática Descriptiva de la Lengua Española, Madrid, Espasa-Calpe, pp. 363-393.

ReAl ACADEmia EsPañola (en línea): Nuevo Tesoro lexicográfico de la lengua española, http://www.rae.es

- (2001): Diccionario de la lengua española, Madrid, Espasa-Calpe. [DRAE] (2009): Nueva gramática de la lengua española, Madrid, Espasa. [NGRAE]

RAINER, Franz (1993): Spanishe Wortbildungslehre, Tubinga, Niemeyer.

RIBERA, Julián (1918): «Los nombres de acción en el Diccionario actual de la Academia», Boletín de la Real Academia Española, V, pp. 281-297.

SANTIAGo Lacuesta, Ramón y Eugenio Bustos Gisbert (1999): «La derivación nominal», en I. Bosque y V. Demonte, dirs., Gramática descriptiva de la lengua española, Madrid, Espasa-Calpe, pp. 4505-4594.

SECO, Manuel et al. (1999): Diccionario del español actual, Madrid, Aguilar. [DEA]

VAN HOUT, Angeliek (1991): «Deverbal nominalization, object versus event denoting nominals, implications for argument \& event structure», en F. Drijkoningen y A. van Kemenade, eds., Linguistics in the Netherlands 8, Amsterdam, John Benjamins, pp. 7180. 